\title{
Are There Any Intrinsically Unjust Acts?
}

\section{Roger Teichmann}

\begin{abstract}
In 'Modern Moral Philosophy', Anscombe characterises the virtue of justice by reference to two features of the just person: (a) that of having a standing intention not 'to commit or participate in any unjust actions for fear of any consequences, or to obtain any advantage, for himself or anyone else'; and (b) that of being someone who 'quite excludes' certain types of action from consideration (viz. intrinsically unjust ones). I investigate what (a) and (b) together amount to and entail. The investigation covers a number of issues, including the nature of moral dilemmas, the relevance or irrelevance of motive to the question whether an act manifests a given virtue (e.g. justice), backward-looking reasons and practical wisdom (phronesis), and the idea of moral bedrock, or moral 'hinge propositions'. I conclude with a tentative endorsement of the view that there are intrinsically unjust kinds of acts, i.e. acts that are always and everywhere unjust.
\end{abstract}

Keywords Anscombe $\cdot$ Justice $\cdot$ Dilemmas $\cdot$ Absolutism $\cdot$ Consequentialism

In 'Modern Moral Philosophy' (henceforth $M M P)^{1}$ Elizabeth Anscombe famously argued for three theses: that moral philosophy should be laid aside until we have an adequate philosophy of psychology; that the concepts of moral obligation and moral duty, and of what is morally right and wrong, and of the moral sense of 'ought', ought to be jettisoned if this is psychologically possible; and that the differences between the well-known English writers on moral philosophy from Sidgwick to the present day (i.e. 1958) are of little importance.

\footnotetext{
1 In Anscombe 1981b, 26-42.

R. Teichmann $(\bowtie)$

St Hilda's College, University of Oxford, Oxford, UK

E-Mail: roger.teichmann@st-hildas.ox.ac.uk
} 
The reason for her third thesis relates to that trend in modern moral thought which Anscombe dubbed 'consequentialism'. Consequentialism, she argued, is incompatible both with the ethical tradition at the heart of Western culture, the HebrewChristian ethic, and with ancient Greek thought. In both these traditions we find the belief that certain things are ruled out absolutely - such things as killing the innocent, vicarious punishment, and treachery (MMP 34, 41). Consequentialism abandons such ethical absolutism, an abandonment which Anscombe regarded as a disaster. Any differences between modern, consequentialist positions must therefore appear trifling in comparison with their ominous similarity; this is the purport of her third thesis.

To say that killing the innocent is absolutely ruled out is not, for Anscombe, to allege an absolute 'moral obligation' not to kill the innocent; for (as her second thesis proposes) the language of 'moral obligation' is, for various reasons, best avoided. Rather, the typical ground for saying that something is absolutely ruled out is that it is intrinsically unjust. Generally speaking, talk of moral obligation, where by such talk someone is attempting to say something worth saying, can be replaced by talk of justice and injustice (MMP 38-41). And talk of absolute moral obligation is typically to be replaced by talk of intrinsic injustice.

In this article, I aim to examine what Anscombe means by 'intrinsic injustice', and what can be said for her view that there are intrinsically unjust types of act i. e. types of act which are absolutely ruled out. I am not primarily setting out to defend some philosophical claim. I intend rather to explore a range of issues thrown up by Anscombe's discussion, including: what being a just person consists in; the nature of moral dilemmas; the relevance or irrelevance of motive to the question whether an act manifests a given virtue (e.g. justice); backward-looking reasons and practical wisdom (phronesis); and the idea of moral bedrock, or moral 'hinge propositions'. Some of the investigation will naturally deal with how Anscombe should be read and what her overall position looks like, but the ultimate goal is philosophical and ethical understanding. Those who would like to know the (rough) outline of the discussion to come may like to consult the final section of this paper, which contains a synopsis.

\section{I.}

Anscombe distinguishes between 'the intrinsically unjust, and what is unjust given the circumstances' (MMP 38). Taking and using someone's property without that person's permission is typically unjust, but circumstances may render it just (or not unjust) - such as when 'you could use a machine of his to produce an explosion in which it would be destroyed, but by means of which you could divert a flood or make a gap which a fire could not jump' (MMP 39). By contrast, procuring the judicial execution of an innocent person is intrinsically, i.e. always and everywhere, unjust.

How shall we define or characterise justice? One way of taking this question is as one having to do with a certain virtue, a human disposition of character. While disclaiming the ability 'to do the philosophy involved', Anscombe nevertheless takes 
it to be 'clear that a good man is a just man; and a just man is a man who habitually refuses to commit or participate in any unjust actions for fear of any consequences, or to obtain any advantage, for himself or anyone else.' (MMP 40) Hence, among other things, the just man will habitually refuse to procure any judicial executions of any innocent persons, for whatever reasons.

The sentence 'Smith refuses to commit any unjust actions' can be taken in two different ways, in one of which 'refuses' takes wider scope, in the other of which 'any' does. If 'any' takes wider scope, the sentence means, roughly, 'Every time Smith is faced with the possibility of committing an unjust act he refuses to do so', or 'Smith eschews every unjust option'. Adding the adverb 'habitually' to such a proposition produces a grammatical peculiarity: 'Smith habitually eschews every unjust option' - akin to 'Smith habitually never takes bribes'. The adverb 'habitually' modifies action-verbs (including inaction-verbs), and 'eschews every unjust option' is not, we might say, a proper action verb.

That Anscombe uses 'habitually' is explained by her seeing the issue as one concerning a person's habits or dispositions, i. e. his character; but to ascribe a habit or trait of character is not to allege an exceptionless generalisation about a person, and 'habitually' does not mean 'always'. In the domain of human action, 'always' is ruled out by those exceptions or failures that arise from being tempted, being terribly provoked, being drugged or hypnotised - or even undergoing a change in character. In such cases a person who habitually $\varphi$ s does not $\varphi$.

There are thus two reasons for interpreting 'habitually refuses to commit or participate in any unjust actions' in such a way that 'refuses' (and not 'any') takes wide scope: to avoid a logico-grammatical infelicity, and to avoid the conceptual clash between 'habitually' and 'always'. ${ }^{2}$ We should, I suggest, read the occurrences of 'any' in Anscombe's statement as occurring in an intentional context set up by the verb 'refuses'. That is to say, we are to imagine the just man habitually saying or thinking, 'I will not commit or participate in any unjust actions for fear of any consequences (etc.)'. This would be compatible with his in fact, one day, performing an unjust action. If he does so, we may presume that one of the possibilities we have mentioned obtains - e.g. extreme hunger has driven him to snatch the bread from a fellow prisoner's hands. (Later on we will be considering another possibility: that of a just man's committing an unjust act because faced with a dilemma between two unjust courses of action.)

It is natural to think that if a habitually just man does one day commit an injustice he will (unless he is non compos mentis or has suffered a character-change) feel regret, remorse, or the like; and that his feeling regret is in fact a criterion of his being a just man. Knowing all this, a just man aware of his own virtue might say, 'I will not commit or participate (etc.)... but if one day I do, and have not become a different sort of person, I shall feel regret for what I have done.' His 'I will not...' is an expression of intention, his 'I shall feel...' is a (conditional) prediction, or as Anscombe puts it in Intention, estimate (Anscombe 1963, sec. 2-3). The difference between expressions of intention and estimates of what one will do lies especially

\footnotetext{
2 The logico-grammatical infelicity is independent of the conceptual clash, as can be seen from the fact that it is also found in the sentence 'Smith habitually eschews almost every unjust option'.
} 
in the different sorts of grounds one gives for the two sorts of statement, i.e. the different sorts of answer one gives to 'Why?'3

'If one day I do, then I shall feel regret' is only a conditional prediction. But couldn't someone have grounds for thinking that he will do something regrettable? He might know that extreme temptations or provocations await him; he might know he is going to be threatened with torture by people wanting him to betray his companions. Anscombe discusses this kind of situation in the final section (sec. 52) of Intention, writing that 'if one is considering the fact that one may not do what one is determined to do, then the right thing to say really is "I am going to do this...unless I do not do it".' (Anscombe 1963, 93) She goes further: '...in some cases one can be as certain as possible that one will do something, and yet intend not to do it' (ibid., 94) - which would appear to warrant one's saying 'I will not do this, but I shall do it.'

Perhaps Anscombe goes too far here. Someone's being as certain as possible that she will do something may be thought to rule out her intending (or properly expressing the intention) not to do it. Be that as it may, it is surely humanly possible for someone who intends not to $\varphi$ nevertheless to have grounds for fearing that she may (well) not be able to adhere to her intention. And her 'intention not to $\varphi$ ' might be the intention characteristic of the just person, viz. not to commit or participate in any unjust actions for fear of any consequences, or to obtain any advantage, for herself or anyone else.

We have seen that for intrinsically unjust acts, Anscombe's just man will have a standing intention not to $\varphi$, where ' $\varphi$-ing' is an act-description of a more specific kind than 'doing what is unjust' - e.g. 'procuring the judicial execution of an innocent person'. Anscombe indicates that such an action as procuring the judicial execution of an innocent person 'should be quite excluded from consideration' (MMP 40). She evidently sees such a stance of exclusion as being a part of the virtue of justice. Given the human possibilities of temptation, provocation, etc., the just man will quite exclude certain kinds of action from consideration while not excluding the real possibility of performing such actions.

Here it might be asked: 'So what is it to exclude certain types of action from consideration?' A possible answer would be: 'Consideration means deliberation; a person acting and thinking justly will, in the course of deliberating what to do, refuse to consider (as something that might have its pros and cons) an action of suchand-such type, or of such-and-such type....' Of course the man who cracks under torture or the starving woman who snatches a fellow prisoner's bread are hardly likely to have deliberated what to do. Are we then to say that unjust acts must be deliberate? - that where severe temptation, provocation, etc. exclude deliberation, a person cannot act unjustly?

\footnotetext{
3 The obvious answer to 'Why will you feel regret if you do that?' will in fact give a reason, in the sense of 'reason' which is at the centre of Anscombe's account of intentional action: for it will be something like 'Because doing such a thing is unjust'. But this is the reason for the predicted regret, i.e. the answer that might later be given to the question 'Why do you feel regret?' The reason for the man's prediction, i.e. for his belief, is not this, but has to do with his view of his own character.
} 
This would be too quick. Justice is not only put to the test in situations where the agent actually deliberates. After all, deliberation can in some sense be excluded by ordinary haste or thoughtlessness, and in such cases we can still call what is done unjust, adding only that the person should have thought more carefully, perhaps even should have deliberated. 'Should' implies 'could', it might be said; and in what sense could a hasty person have deliberated while a starving person could not? The question is a difficult one, and is among other things connected with the (in)voluntariness of (not) thinking certain thoughts. ${ }^{4}$ But it need not detain us here, since the answer to it does not directly impinge on our topic, namely whether it is necessary for being a just person that when you do deliberate what to do, you habitually refuse to consider various kinds of (unjust) options.

The virtue of justice, according to this picture, involves a negative habit: the habit of not allowing certain sorts of action to figure as options on a deliberative agenda. Now one might have such a habit though one never forms the judgment 'No deliberative agenda may include such-and-such options'. An analogous possibility exists for inductive belief: a person or creature can be in the habit of forming particular expectations on the basis of particular observations or experiences, without ever forming any general judgement of the form 'Whenever p, q'. - 'But wouldn't that just show that the creature was unreflective? Shouldn't a reflective creature who has such a habit be led by reflection to form the general judgement?' The claim is dubious. I habitually sit on chairs with a confidence expressive of the belief 'This chair won't collapse under me'; but reflection does not led me to endorse the generalisation, 'No chair will ever collapse under me', still less 'No chair will ever collapse under somebody.'

It seems that a reflective person might have the negative habit belonging to the virtue of justice without forming a corresponding general judgment. But it still might be thought that the negative habit is not enough, and that a just person ought to say or think, 'No deliberative agenda may include such-and-such options.' Anscombe's characterisation of the just person does not entail this. But as the above discussion of 'habitually' and 'any' indicates, her just man will say or think 'I will not commit or participate in any unjust actions for fear of any consequences (etc.)'; and as regards intrinsically unjust acts, it might naturally be supposed that he will not only think such a thought, but also the thought 'I will not allow any such actions to figure among the options on my deliberative agendas' - a commitment tantamount to 'May no deliberative agenda of mine ever include such options'.

However, 'May no deliberative agenda of mine include...' differs from 'No deliberative agenda of mine may include...' The first is an optative or third-person imperative; the second uses 'may' as a modal verb, and the whole sentence can be read as containing a 'stopping modal', being equivalent to 'Deliberative agendas of mine must not include...' ${ }^{5}$ The first statement can be rephrased in the first person, as 'May I not/never include on any deliberative agendas...' This shows why it expresses the same commitment as the expression of intention, 'I will not...', so that it too may

\footnotetext{
${ }^{4}$ For a discussion of the voluntariness of thoughts, see Teichmann 2014.

5 For Anscombe's terminology of 'stopping modals', see e.g. her 'Rules, Rights and Promises' (Anscombe 1981b, 97-103).
} 
be attributed (as a possible thought or utterance) to the just person. Nothing that has been said so far warrants our attributing to the just person the 'stopping modal' judgement. The paradigm use of stopping modals is within rule-governed practices, such as games, where a 'must not' is backed up by what Anscombe calls a logos (e.g. 'my queen is attacking your king', or 'that bicycle isn't yours'). The logos is partly what distinguishes the stopping modal from a mere imperative. No logos appears forthcoming to back up the statement 'No deliberative agenda of mine may include...' ${ }^{6}$ One might respond to such a statement, 'Why not? According to what rule?' A Kantian will perhaps look for a principle of reason to answer that question, but Anscombe is not one to follow the Kantian here - and nor do I.

\section{II.}

As we saw above, cases where a just person does commit an injustice will, for Anscombe, be ones where she fails - where for some reason she has not the strength to adhere to her overriding intention not to commit or participate in unjust actions. She is then likely to feel regret for what she has done. These two features of the situation - failure ('coercion of will', etc.), and regret - are absent from the situation in which a person decides to adopt an unjust choice as 'the best thing to do', especially on the basis of a calculation of consequences.

Anscombe is famously critical of consequentialist reasoning about whether to commit injustices. And her aversion to such reasoning carries over to an aversion to framing hypothetical extreme scenarios in which a blanket refusal to consider doing what's intrinsically unjust is put under pressure. In 'Modern Moral Philosophy' she writes: 'the point of considering hypothetical situations, perhaps very improbable ones, seems to be to elicit from yourself or someone else a hypothetical decision to do something of a bad kind.' (MMP 37) A bit later in the article she states her objection more directly, in a footnote:

In discussion when this paper was read, as was perhaps to be expected, this case was produced: a government is required to have an innocent man tried, sentenced and executed under threat of a 'hydrogen bomb war'. It would seem strange to me to have much hope of so diverting a war threatened by such men as made this demand. But the most important thing about the way in which cases like this are invented in discussions, is the assumption that only two courses are open: here, compliance and open defiance. No one can say in advance of such a situation what the possibilities are going to be - e.g. that there is none of stalling by a feigned willingness to comply, accompanied by a skilfully arranged 'escape' of the victim. (MMP 40, footnote 6)

It is clearly a real objection to say: 'A case like this needs to be spelt out in detail if we are to know what the best course of action would be; and to arrive at a conclusion about that in advance of looking at any such details is wrong-headed:

\footnotetext{
${ }^{6}$ The phrase 'of mine' is odd, of course. The point made here applies equally to 'No deliberative agenda may include...'.
} 
practically wrong-headed if you find yourself in such a situation, and philosophically wrong-headed if you are thinking about it hypothetically.' But if 'no one can say in advance of such a situation what the possibilities are going to be', then no one can say in advance that there will be any possibilities of stalling, feigning, or of similar ruses. The details of a case surely might rule out all such possibilities. We need not conclude that in that case only the 'weighing of consequences' can help us; the situation might instead wear the guise of a genuine dilemma, maybe even a dilemma between two courses of action each of them unjust - or at any rate prima facie unjust.

In an unpublished and undated typescript which appeared posthumously under the title 'Two Moral Theologians', Anscombe addresses the topic of moral dilemmas (Anscombe 2008). ${ }^{7}$ She writes: 'That if you can see no possibility except to give some information you must not give, or to lie, you will do better to lie than, say, to betray the unjustly persecuted fugitive - this is sufficiently obvious.' (ibid. 163) But she takes the fact that a person can't see a way out of such dilemmas as indicating his imperfection; for it remains true that to lie is sinful. Of the question whether in such cases it is possible to 'avoid any sin at all', she says: 'the truth is: you might not be good enough to do that'.

Perhaps a moral dilemma is a situation where whatever you do you end up spoiling your life, leaving a blot on it. But it isn't so clear that being, or acting, in such a situation implies any imperfection of character: why must it be a question of a person's not being good enough to see how to avoid sin? That goodness of character need not be at issue seems to come out in what Anscombe herself writes a bit later on: 'If you cannot see any alternative to committing one sin or another, you act better if you choose the lesser sin. And you may not have time or cleverness to find out a better possibility.' (ibid. 164) Lack of time or cleverness can hardly be taken as indicative of defect of character, particularly lack of time. And the same must surely be said of an inability to see (= think of) practical routes available in what could, after all, be a situation both novel and surrounded by constraints.

It would also need arguing that even where one cannot see a way out of a moral dilemma there will always be such a way. At Corinthians 10.13, St Paul says, 'But God is faithful; He will not suffer you to be tempted beyond that which ye are able to bear, but with the temptation will also make a way to escape, that ye may be able to bear it.' Could a Christian interpret 'a way to escape' as pointing to such ruses as stalling and feigning? The passage surely suggests, rather, that Paul has in mind situations in which what is put to the test is someone's strength of will, their ability to withstand the force of certain temptations. So this passage, at any rate, seems not to be one which, as a Christian, Anscombe would have reason to quote in her defence.

It seems to me impossible to maintain that in every moral dilemma of the sort we are considering there will in fact be a 'way out' for a just person. This indeed appears to be a consequence of the fact mentioned by Anscombe herself, that "no

\footnotetext{
7 The essay discusses the writings of Arthur Vermeersch and Bruno Schüller. Since in it Anscombe uses the term 'consequentialist', which she had first introduced in $M M P$, we may infer that this article was written later than $M M P$.
} 
one can say in advance of such a situation what the possibilities are going to be'. But if I am right about that, it does not follow that the virtue of justice cannot be seen as Anscombe sees it, as involving the standing intention not 'to commit or participate in any unjust actions for fear of any consequences, or to obtain any advantage, for himself or anyone else'. It is true that things will begin to look worrying if insoluble dilemmas between unjust courses of action are conceivable. If such dilemmas are possible, then the just man who finds himself facing one will be unable to abide by his intention; and in grasping one horn of the dilemma, he will presumably be opening himself up to regret or something like it. A dilemma like that between taking another's property and diverting a flood will not be of this sort, since in such a case, if Anscombe is right, an act-description which typically entails injustice does not do so (i.e. the act-description 'taking another's property without his permission'). Nor are we thinking of dilemmas where each horn is prima facie unjust and where it is indeterminate which one represents the best option, such indeterminacy resulting from the non-algorithmic nature of practical wisdom; for unless each prima facie injustice is an intrinsic injustice (in which case the phrase 'prima facie' is out of place), the person who chooses one horn of the dilemma may surely point to the other horn as constituting a circumstance analogous to that of the need to divert a flood - i.e. as nullifying the description of what he does as 'unjust'.

Thus if there are insoluble dilemmas between unjust courses of action, they are dilemmas between intrinsically unjust courses of action. Now the difficulties surrounding this idea are fairly obvious. Philippa Foot agrees with Anscombe that some kinds of action are absolutely prohibited (i.e. that their performance will always be vicious, necessarily detracting from the agent's goodness as a human being). But she argues against the thesis

...that two absolute moral prohibitions, which will relate to intentional actions, could conflict. For however terrible the inescapable choices that people have to make, they will never be between two intentional actions, as, for instance, torturing $X$ and torturing $Y$, but only between torturing $X$ and not preventing another from torturing $Y$, or from bringing about some other horrible result.

(Foot 2002, 188)

For Foot, intrinsically unjust actions will be intentional actions; they will not be non-preventions. Anscombe's example of the unjustly persecuted fugitive appears to show, by contrast, that she thinks that not preventing unjust pursuers from finding a fugitive might count as betrayal, and hence as unjust; but the passage in question is not entirely clear on this point, since Anscombe describes one horn of the dilemma as 'giving some information you must not give' (a type of intentional action). If the dilemma could be avoided simply by doing nothing, then it would seem strange for Anscombe to dwell on the phenomenon of a person's seeing no possible way out, given that doing nothing is always an obvious option. Hence I am inclined to think that she did believe in the conceivability of dilemmas between intrinsically unjust courses of action, at least at the time of writing 'Two Moral Theologians'. She did not, however, think of these dilemmas as insoluble, since she took it that there would have to be some 'way out', such as a feint or a ruse. This thought, I have argued, lacks justification, and indeed credibility; but without it, the claim that 
such 'tragic' dilemmas are conceivable leads to the conclusion that even a perfectly just and wise person can end up doing 'the wrong thing'. And as Foot writes,

...if we want to accept 'wrong if you do, wrong if you don't' as an intelligible possibility, and still keep [the] negative relation between doing what is wrong and personal goodness, we have to revamp the latter notion to make that goodness vulnerable to the "taint" of involvement in a horrifying, humiliating, or tragic situation, or to the hatred of the gods; and then say that a choice that involves such badness is "wrong".' (ibid.)

\section{III.}

Two questions face us. First, why should it be thought a virtue to have these two characteristics: (a) maintaining a standing intention not to commit or participate in any unjust actions (etc.), and (b) being someone who quite excludes certain types of action (viz. intrinsically unjust ones) from consideration? Second, why should we think there are any intrinsically unjust types of action?

It could be argued that a person who is temperate in her eating has a standing intention not to go in for any gluttonous actions, for whatever reasons. She might on some occasion choose to eat an enormous amount, for instance if the customs of the country she is in make it likely that her hosts (who have piled her plate with sweetmeats) will strongly resent her leaving any food untouched. But in this scenario her eating will not count as gluttony: for her motive is not foodie bliss, but avoidance of conflict. So she has abided by her standing intention.

We might sum this up by saying that there are no 'intrinsically gluttonous' acts; but seemingly this can only be true if there is a limit on how detailed the descriptions of types of act can be - for a sufficiently detailed description of an act of eating, one that includes description of the surroundings, the lead-up to the act, etc., may in practice rule out any motive other than foodie bliss. I say 'in practice', since it is arguable that the list of possible defeating conditions (conditions which would defeat the verdict 'gluttonous') is an open-ended list, of the sort described by Anscombe in 'On Brute Facts' (Anscombe 1981b, 22-25). If we do say that about the list of possible defeating conditions, we shall be able to stick to 'There are no intrinsically gluttonous acts'. And for similar reasons we may, following Anscombe, say 'There are no intrinsically larcenous acts'. ${ }^{8}$ In what follows I will assume that these are things we do want to say.

The fact that there are no intrinsically gluttonous types of act is what enables us to claim that a person who is temperate in her eating has a standing intention not to go in for any gluttonous actions, for whatever reasons. The trick pulled here will not work for any virtue-concept, however. It works for temperance because of the importance of motive for deciding whether something counts as gluttonous. The concept of tidiness, for example, looks rather different. Consider a habitually tidy person who is enrolled by the secret service, and is one day required to leave his

\footnotetext{
8 'Thievish', if you prefer.
} 
flat in a complete mess to make it seem as if he is an alcoholic going off the rails (hence appearing to be easy prey for the other side's agents). He has certainly left his flat untidy - has in fact failed to be tidy. He has been deliberately untidy. Here motive is irrelevant. Some courses of action just are intrinsically untidy, and motive has nothing to do with it.

The difference between temperance and Anscombe's version of justice lies (in part) in the non-existence of intrinsically gluttonous kinds of act and the existence of intrinsically unjust kinds of act. We saw that whether eating a huge amount counts as gluttonous depends on the motive with which it is done, and something similar seems to go for those sorts of act which can be sometimes unjust, sometimes just: it is the motive that the flood be diverted, e.g., which turns what would otherwise be an unjust use of someone else's machine into a just use of it. And it might be now asked: why may not the motive behind judicially executing an innocent man be relevant to whether it counts as just?

Anscombe writes:

No circumstances, and no expected consequences, which do not modify the description of the procedure as one of judicially punishing a man for what he is known not to have done can modify the description of it as unjust. Someone who attempted to dispute this would only be pretending not to know what "unjust" means: for this is a paradigm case of injustice. (MMP 39)

Paradigm cases lie at the centre of concepts: where a person's very mastery of a given concept, F, involves knowing (or: being able to say) 'This is an F, if anything is', the 'this' in question counts as a paradigm case. Hence denying that a paradigm case of an F is an F shows either that you are not master of the concept, or that you are 'only pretending not to know what "F" means'.

Anscombe's argument appears to run: "The concept "just" is such that $\mathrm{X}$ is a paradigm case of injustice; so $\mathrm{X}$ is always and everywhere an injustice; so what motive a person has cannot prevent an instance of $\mathrm{X}$ from being an injustice.' The term ' $\mathrm{X}$ ' here denotes a kind of act, or course of action: here, judicially executing an innocent person.

Roasting a chicken is a paradigm case of preparing food, but not every case of chicken-roasting is a case of preparing food. One might roast a chicken so that it can sit on a table as a realistic prop in a play. 'Well, that particular chicken-roasting wasn't a paradigm case of preparing food, then.' What follows if we agree to that statement? Surely not: roasting a chicken is not a paradigm case of preparing food. The lesson of 'On Brute Facts' is once again relevant; the list of defeating conditions on whether some action is a case of food-preparation is indefinitely open-ended. If we insist on talking of all instances, we shall have to say that every chicken-roasting performed in normal (ordinary) circumstances is a case of preparing food, and the open-endedness is now simply embodied in the concept normal.

Where there is an analytic connection between the concept $\mathrm{F}$ and the concept G, Gs being paradigm cases of Fs, then for sure, every G must be an F. Tomcats are paradigm cats; and every tomcat is a cat. But this is because of the definitional connection of 'tomcat' and 'cat'. Anscombe cannot, I think, be alleging that sort 
of connection as holding between 'judicially executing an innocent person' and 'unjust'.

Well, maybe the move from 'The concept "just" is such that judicially executing an innocent person is a paradigm case of injustice' to 'Judicially executing an innocent person is always and everywhere an injustice' is not as it stands quite safe. But surely what Anscombe is really saying is: doing this is going to count as unjust regardless of the agent's motive? And that sort of thing can be said elsewhere, after all, as we saw in the case of untidiness. Intentionally or voluntarily leaving your flat in a mess is being untidy, whatever your motives.

But that very fact about untidiness is what makes it seem wrong to claim that the tidy person quite excludes untidy types of action from consideration. A tidy person can easily (and properly) allow that untidiness might on a given occasion be acceptable, even required. If certain sorts of action simply have injustice written into them, so to speak, how can we claim that it is a virtue to exclude those types of action from all consideration? - a vice not to exclude them? (I assume that to lack justice is to be to that extent vicious.) It cannot just be that questions of justice and injustice are much more important than questions of tidiness and untidiness, for importance can often outweigh importance, as when one takes someone's expensive machine and uses and destroys it in the course of diverting a flood. One does not do such a thing lightly - but still, one does it.

\section{IV.}

To make headway with this problem we should turn to the motives behind actions that are performed from justice - actions that are just in a sense that goes beyond being 'not unjust'. (Here, 'actions' include not-doings.)

A major reason why calculation of consequences often looks out of place in deliberative situations to which considerations of justice are relevant is this: the virtue of justice relates especially to reasons for action that arise from present or past facts. An important sub-class of these are those institutional (i.e. practice-based) facts that are paradigmatically expressed using stopping and forcing modals - 'You can't take that, it's not yours', 'He didn't do it, so you can't punish him for it', 'She should do it since she promised to'. Again, the just person who has erred against justice will feel called upon to express regret or remorse in such terms as, 'I am sorry; I lied to you', and behind this utterance lies the thought, 'I did such-andsuch: I must apologise'. Justice itself requires our apology, and the 'must' belongs to a human practice, that of making apology.

An institutional 'must' or 'cannot' may be overridden by facts having to do with consequences. 'You cannot take another's property without his permission' may be overridden by 'Only by doing so in this situation can we divert the flood'. But one who decides to act against the 'cannot' won't have done so by calculating or estimating the badnesses of two outcomes and choosing the lesser. The badness of ignoring the rule about property doesn't reside in any consequences of doing so, in the sense of 'effects brought about by doing so'. Nor does it if we expand the sense 
of 'consequences' to include what might be naively called 'the act itself'. ${ }^{9}$ Talk of 'badness' here is indeed clumsy; what is true is that understanding 'You cannot take another's property without his permission' involves taking it as a reason against $\varphi$ ing that if you $\varphi$, you take another's property without his permission. ${ }^{10}$ How then do I weigh the reason for not taking another's property against the reason in favour of diverting a flood?

The answer to this need not - cannot, I would say - advert to any calculus or currency, any single 'scale of value'. For the two reasons for action are of radically distinct types. After all, even consequential or forward-looking reasons can be incommensurable. In the market-place you are asked to pay $£ 60$ for a rug; you say 'I'll give you $£ 45$ '; the vendor says ' $£ 50$ ' - whereupon you say 'OK... or I could invite you to be a guest at my daughter's wedding.' A classical utilitarian will insist that the vendor must now calculate the amounts of something, e.g. pleasure, available to him from each choice, if he is to decide on anything. But this 'must' is the 'must' expressive of enchantment by a philosophical picture. What the utilitarian claims is a truth neither of reason nor of experience, as Hume might have put it. So what does go on in the mind of the vendor? Perhaps he spends a moment imagining being at a wedding; if he knows who else is likely to be there he can imagine it in more detail, of course. He may ask himself whether the offer made him is an affront, or insincere. Or he may just laugh and repeat his offer of $£ 50$. Nothing more need happen. To say that something else must happen, maybe subconsciously, is simply to express adherence to the above-mentioned picture (one that was pretty thoroughly explored by Wittgenstein in his later writings, by the way).

The vendor's possible reasons for action are all of them to do with consequences: they are forward-looking. In situations where one of the reasons in play is forwardlooking and the other is backward-looking, e.g. relating to a promise made, the notion of a quantitative calculation is even more out of place. Now an expectedutility decision-theorist may stipulate that the value ascribed by Mary to keeping her promise has a precise quantity, being equivalent to the smallest sum of money she would accept in lieu of keeping it. (And if she'd accept no sum, then she ascribes infinite value to keeping it.) Insofar as the point of the stipulation is to allow for interpersonal comparisons of 'utility', it assumes that everyone ascribes the same,

\footnotetext{
9 John Broome writes, 'If you break a promise, one consequence will be that you have broken a promise, and the wrongness of promise breaking can be taken as a bad feature of this consequence...In this way, the intrinsic value of acts can be absorbed into teleology.' (Broome 1995, 4.) 'Teleology' is the form of utilitarianism Broome is defending. - If I keep a promise, then it must be under the description keeping a promise that my action is to be made out as having intrinsic value; for it probably won't have any intrinsic value, except accidentally, under some such description as bringing Smith a book. But one could argue analogously that under the description providing for my descendants the action of investing my money in a certain way has intrinsic value. This latter way of talking would usually be ruled out by distinguishing the value an act has in itself from the value it has on account of what happens subsequently (especially what happens as a result of the act); and similarly, one ought to distinguish the value an act has in itself from the value it has on account of what happened earlier.

${ }^{10}$ In the background is the fact that it is good for human beings to have and abide by the institution of property - better than not having it (at least 'in the nearest possible world'). But this good, consequent upon there existing the institution, does not and cannot play a part in any consequential deliberating by an individual agent.
} 
positive, value to money - after all, everyone knows that money is exchangeable for anything you want! (Thinking that money is the root of all evil must be radically confused.) But more pertinently to our topic: such a manoeuvre could only show that, for Mary, a certain forward-looking reason could, hypothetically, override the backward-looking one. This we already knew to be possible. The question is how Mary arrives at her decision. That she one day opts for the money doesn't mean that she is operating with a single scale or calculus; that she would do so, hypothetically, even if there is a fact of the matter about that at all, shows even less.

If it is possible for human beings to decide between conflicting reasons for action (i.e. reasons for incompatible courses of action) without their employing a single scale of value, how do they do it? This question is rather like: how do human beings hear the direction from which a sound comes? Typically you do not employ a method for detecting where a sound comes from, and if asked 'How did you do that?' would have to reject the question - or interpret it as a question not about methods but about your constitution, your faculties. If you are knowledgeable, you will advert to the slight temporal difference between when a sound reaches one ear and when it reaches the other. No physiological answer can be given to the question at the head of this paragraph, of course. But we can also take that question as asking about our faculties. Taken as a question about methods it can only be met by an entirely uninformative answer, along the lines of 'By thinking carefully about the salient issues - sometimes'. Taken as a question about our faculties, the answer also hardly informative - will be: human beings have common sense, or practical wisdom. (Those are not synonyms, by the way.)

The faculty of practical wisdom differs from that of directional hearing in that there is an independent test for where a sound is coming from - independent, that is, from verdicts made on the basis of where we hear it as coming from. There is not in that sense an independent test for whether it would indeed be right to choose to divert the flood rather than avoid using another's property. It does not follow that such a choice is merely subjective - that there's no such thing as going wrong. Here, roughly speaking, objectivity arises from the twin phenomena of intersubjective agreement and a social practice of giving and comparing reasons. Such an account of objectivity will be familiar, having been explored and spelt out for a variety of discourses, not least ethical ones. I will not dwell on it here, but will rather return to the question: What is to rule out a just person's taking certain e.g. consequential reasons as overriding the reason 'He did not commit the crime' (when deliberating whether to punish someone)?

Practical wisdom is the faculty, among other things, of knowing when one reason for action overrides another, and this can include cases of a forward-looking reason's overriding a backward-looking one, as we have seen. Now Aristotle was surely right to think that practical wisdom (phronesis) cannot be taught by means of instruction, e. g. in rules: a person must acquire, through experience of life and reflection on it, a kind of sensibility, or rather kinds of sensibilities, enabling him to know when a concept like 'lying' truly applies, for example. So when someone asks 'Why is it sufficient reason to take his machine that you can thereby divert a flood?', nothing like a proof or demonstration is going to be available, and such remarks as can be given by way of reply will only persuade someone who himself has an 
adequate degree of practical wisdom. This means that it is open to Anscombe to say that 'Why can't we punish this innocent man to avert a riot?' (e.g.) can only be answered with 'reminder-like' remarks whose force will appear adequate only to those with practical wisdom.

\section{V.}

The problem is that Anscombe is committed to a blanket assertion: that there can be no practical reason that could override 'The man is innocent' so as to favour the conclusion 'Let us punish him'. ${ }^{11}$ So far, practical wisdom has been invoked only as the faculty enabling us to 'weigh' particular reasons against each other; can it also be credited with seeing in advance that no such weighing could ever lead to a certain practical conclusion?

We have seen that Anscombe regards it as possible that someone should be in a situation where he faces two choices, each of them unjust. It was of such a situation that she wrote: 'That if you can see no possibility except to give some information you must not give, or to lie, you will do better to lie than, say, to betray the unjustly persecuted fugitive - this is sufficiently obvious.' I suggested above that there seems no good reason to suppose that in every case where you cannot see a way out of a moral dilemma, there must nevertheless be one; and, in addition, that one's not being able to see a way out (even where there is one) needn't betoken a defect of character - neither a defect in justice nor a defect in practical wisdom. ${ }^{12}$ If I am right, there may in principle be a dilemma between two courses of prima facie unjust action, one horn of which is judicially executing an innocent man, such that one who cannot see a 'way out' is not therefore to be counted an unjust person - where 'ways out' are ways of jumping between the horns of the dilemma (by adopting feints, ruses, etc.). But of course it might, for all that's been said, still be 'sufficiently obvious' that one must not execute the innocent man.

The issue seems to be one of onus of proof. Is it for Anscombe to show us why there can be no practical reason that could override 'The man is innocent', or for her opponent to show us that there can be such a reason? On the face of it, it would look more reasonable to require the second, not the first, if only because the truth of a negative generalisation is harder to demonstrate than that of an existential statement. One might of course decline to pass judgment either way in the absence of persuasive grounds. It seems in any case clear that Anscombe regards as morally (not just intellectually) beyond the pale the philosopher who, without showing why or how, claims that there can be a practical reason that could override 'The man is innocent'. Indeed, she goes further than this, describing as 'corrupt' the philosopher

\footnotetext{
11 Anscombe of course refers to the judicial execution of the innocent. She is not, evidently, against execution per se; nevertheless there is a question whether she would absolutely rule out judicial punishment of the innocent. For present purposes, we do best to put to one side the question whether execution per se can ever be justified.

12 Whether Anscombe is right to attach the importance she does to the rule against lying is a further question.
} 
who, without showing why or how, claims that it is an open question whether there could be a practical reason that could override 'The man is innocent':

But if someone really thinks, in advance, that it is open to question whether such an action as procuring the judicial execution of the innocent should be quite excluded from consideration - I do not want to argue with him; he shows a corrupt mind. (MMP 40)

Is the alleged corruption to be understood as a failure to have adopted the stance of the just man, as embodied in the two characteristics mentioned earlier: (a) maintaining a standing intention not to commit or participate in any unjust actions (etc.), and (b) being someone who quite excludes certain types of action from consideration?

It is characteristic (b) which is more immediately relevant. If I am right that 'consideration' means 'deliberation', then Anscombe's just person habitually excludes certain kinds of act (intrinsically unjust ones) from her deliberative agendas, and can be credited with the thought 'I will not allow any such actions to figure among the options on my deliberative agendas' - an expression of intention. Since these are general remarks about what it is to be just, one may conclude 'No just person will, when deliberating justly, allow such actions onto her deliberative agendas.' 'A good man is a just man', according to Anscombe - i.e. only just men are good men. So to think that it is open to question whether such-and-such an action should (always) be excluded from consideration is the same as thinking it open to question whether such-and-such an action would (always) be excluded from consideration by a just person deliberating justly (i.e. abiding by her standing intentions); for in this context, 'should' can only mean 'should, given the aim of being a good person'. But given that such-and-such an action is intrinsically unjust, it cannot be open to question whether it would (always) be excluded from consideration by a just person deliberating justly. To say that it is open to question is to be in the dark either about what justice is, or about the (putative) fact that such-and-such an action is intrinsically unjust, or it is to pretend to be in the dark about these things. Leaving the third case to one side, it might be argued that the other two forms of 'darkness' are symptoms of injustice or less than perfect justice; although the alternative diagnosis, of philosophical darkness, appears to have its attractions. Perhaps moral darkness and philosophical darkness cannot always be disentangled from one another.

'But isn't the question whether procuring the judicial execution of the innocent is intrinsically unjust? The arguments of the previous paragraph are quite ineffective if the answer to that is no.' That is right. And the passage quoted from Anscombe does not contribute anything to that question. I think, in fact, that the 'corruption' Anscombe has in mind is not just a case of 'being in the dark', as described in the last paragraph - something which, in any case, might seem to embody philosophical rather than moral failure. Her complaint comes out in the italicised phrase 'in advance' ${ }^{13}$ Merely saying 'It is an open question whether...' is not what bothers her - it is saying 'It is an open question whether...' in advance of any details of possible cases being given. Perhaps someone might come up with a hypothetical (or

${ }^{13}$ The importance of this phrase in the argument of MMP has been pointed out by Sabina Lovibond; see Lovibond 2004. 
real) scenario and say, pointing to it: 'You see; it's an open question whether certain practical reasons might not outweigh the reason "He didn't commit the crime". Anscombe believes that he will have gone wrong - but at least he will have taken the issue seriously enough to see that the onus is on him to give grounds. Now someone who has come up with such a hypothetical (or real) scenario would not in fact need to speak as tentatively as I have imagined. He could instead say, 'You see; on occasion certain practical reasons would outweigh the reason "He didn't commit the crime".' Hence it appears pointless for Anscombe to have directed her ire at the philosopher who 'really thinks, in advance, that it is open to question whether...' She would have done better to refer to the person who thinks, in advance, that such an action as procuring the judicial execution of the innocent certainly shouldn't be quite excluded from consideration.

We might here wonder why the best course is not that of simply declining to pass judgement on the question whether any practical reason could outweigh 'The man is innocent', in the absence of persuasive grounds either way. For Anscombe's opponent, such grounds would most naturally take the form of detailed descriptions of cases. Anscombe's grounds can evidently not take that form. What form could they take?

Perhaps it is sufficient for Anscombe (a) to go through a number of candidate cases in which it might be made out that there were adequate grounds for executing an innocent man, in each case rebutting the claim; (b) to insist that the onus of proof must (now) be met by her opponent. How else, after all, is one to argue for what seems to one to be a clearly true negative generalisation? How would you argue for the thesis that no one in America has in fact been abducted and later returned to earth by aliens? Those liable to deny that thesis will probably not have the sort of common sense that would enable them to hear your 'reminder-like' remarks as having any force; and no doubt Anscombe feels herself to be facing a similarly deaf opposition when it comes to the issue of executing innocent people.

It is often useful to note the parallels existing between the practical and the theoretical. And it is surely a part of theoretical wisdom - or if you like, of common sense - to say such things as, 'Nothing will induce me to believe that anyone in America has been abducted and later returned to earth by aliens.' The epistemic virtue in question here is flanked by the two vices of excess and defect, called gullibility and scepticism. 'Only a gullible person would believe such-and-such,' we say; and it is an essential feature of the language-game that we should be warranted, sometimes, in refusing to consider various claims at all. Something similar goes for 'Only an excessively sceptical person would disbelieve such-and-such (e.g. that invisible bacteria cause diseases)': we will often be warranted in refusing to take certain doubts seriously.

What is the status of the blanket assertion 'Nothing will induce me to believe that...'? Well, common sense is acquired not through learning specific facts or rules, but through experience and reflection, as was said above. Hence it is in the nature of the case that grounds for such a blanket assertion cannot be given, beyond those paralleling (a) and (b), two paragraphs back. These are facts to which Anscombe can appeal. 
It is worth noting that one who says 'Nothing will induce me to believe that p' is not committed to calling ' $p$ ' a necessary truth - a logical or conceptual truth, for example. We are evidently in the domain of those propositions discussed by Wittgenstein in On Certainty (Wittgenstein 1969), especially those dubbed by commentators 'hinge propositions', after Wittgenstein's remark that 'the questions that we raise and our doubts depend on the fact that some propositions are exempt from doubt, are as it were like hinges on which those turn' (On Certainty sec. 341). Although exempt from doubt, hinge propositions could 'in principle' be overturned, abandoned - but not, it would seem, in ways that we can now spell out as conceivable. When we do attempt to spell out situations where we would be justified in abandoning hinge propositions we either face the riposte 'But what gets judged by what?' ${ }^{14}$ or describe situations where the standards of enquiry - within history, say - themselves start to crumble.

\section{VI.}

It is time to summarise the argument of this paper.

Anscombe characterises the virtue of justice by reference to two features of the just person: (a) that of having a standing intention not 'to commit or participate in any unjust actions for fear of any consequences, or to obtain any advantage, for himself or anyone else'; and (b) that of being someone who 'quite excludes' certain types of action from consideration (viz. intrinsically unjust ones). 'Consideration' means or amounts to 'deliberation'.

As to (a), it seems that an analogous feature can be imputed to the temperate person, this being possible because of the relevance of motive for what shall count e. g. as gluttonous. The point is a conceptual one, and does not, for example, carry over to the concept of tidiness. For Anscombe, motive is sometimes relevant to whether some act shall count as unjust (e.g. in connection with using another's property) - but sometimes it is irrelevant (e.g. in connection with procuring the judicial execution of the innocent). This might be said to make the concept of justice an interesting hybrid.

Those kinds of acts which are unjust regardless of motive (and indeed of any other circumstances) are 'intrinsically unjust'. Their intrinsic injustice fits them to be quite excluded by the just person from her deliberative agendas. This exclusion amounts to a negative habit, but also, presumably, involves a standing intention. There are however no grounds for imputing to the just person the thought 'No deliberative agenda may include such-and-such options', involving as it does a general stopping modal.

The question arises why certain kinds of act are to be deemed intrinsically (always and everywhere) unjust. This question becomes particularly pressing if we allow, as Anscombe does, the possibility of dilemmas between courses of action each of them unjust. Anscombe seems to address the question by allusion to 'paradigm cases'; but if so, her inference from 'Fs are a paradigm case of unjust acts' to 'All Fs are

14 Cf. 'Hume and Julius Caesar' (Anscombe 1981a, 86-92), 89. 
unjust' appears dubious. I argued that a better route to investigating the question was by starting with the observation that justice and injustice frequently, perhaps typically, supervene on past or present facts, e. g. institutional facts of various sorts. This means that there will typically be no 'scale of value' available to the person deliberating what to do, when reasons in favour of one course of action relate to such past or present facts. The only answer to 'How then do people decide what to do when there is a conflict of reasons?' is: 'By using practical wisdom or common sense'. As Aristotle said, practical wisdom is acquired not via instruction but through experience and reflection, and it involves a kind of case-by-case use of reasons.

Practical wisdom, characterised as the virtue employed in the 'weighing of reasons', may allow someone to see, e. g., that there is sufficient reason to take another's machine without his consent if one can thereby divert a flood. But we must ask: can practical wisdom also be credited with enabling someone to see, in advance, that no proper 'weighing of reasons' could ever lead to the practical conclusion 'Execute this innocent man'?

Anscombe could reply affirmatively to this latter question by drawing an analogy between practical and theoretical assertions of the form 'Nothing will induce me to think that p', and also between 'Only a corrupt mind would think...' and 'Only a very gullible/sceptical person would think...' Whether the analogies thus drawn are persuasive is something I have not here gone into (although I myself do find them persuasive). If the status of ' $p$ ' in 'Nothing will induce me to think that $p$ ' is that, roughly, of a hinge proposition, then we might indeed have to say that the claim that justice requires us always and everywhere to exclude from consideration the judicial execution of the innocent is one which - in principle - could one day be abandoned, without this abandonment being a symptom of unwisdom. But the sense of 'in principle' here means that such a 'concession' is compatible with our reasonably ignoring the person who claims, in advance, that there must be reasons (already available from within our rational armoury, so to speak) that could outweigh 'The man is innocent'.

Open Access This article is distributed under the terms of the Creative Commons Attribution 4.0 International License (http://creativecommons.org/licenses/by/4.0/), which permits unrestricted use, distribution, and reproduction in any medium, provided you give appropriate credit to the original author(s) and the source, provide a link to the Creative Commons license, and indicate if changes were made.

\section{References}

Anscombe, G.E.M. 1963. Intention (second edition). Oxford: Basil Blackwell.

Anscombe, G.E.M. 1981a. From Parmenides to Wittgenstein. The Collected Philosophical Papers of G.E.M. Anscombe, Volume I, Oxford: Basil Blackwell; Minneapolis: University of Minnesota Press. Anscombe, G.E.M. 1981b. Ethics, Religion and Politics. The Collected Philosophical Papers of G.E.M. Anscombe, Volume III, Oxford: Basil Blackwell; Minneapolis: University of Minnesota Press.

Anscombe, G.E.M. 2008. Two Moral Theologians. In Faith in a Hard Ground: Essays on Religion, Philosophy and Ethics, ed. M. Geach \& L. Gormally, 157-169. Exeter: Imprint Academic.

Broome, John. 1995. Weighing Goods, Wiley-Blackwell.

Foot, Philippa. 2002. Moral Dilemmas Revisited, In Moral Dilemmas, 175-188, Oxford: Oxford University Press.

Lovibond, Sabina. 2004. Absolute Prohibitions without Divine Promises. In Modern Moral Philosophy, ed. A. O’Hear, 141-158. Cambridge: Cambridge University Press. 
Teichmann, Roger. 2014. 'The Voluntary and the Involuntary: Themes from Anscombe'. The American Catholic Philosophical Quarterly 88/3, 465-486.

Wittgenstein, Ludwig. 1969. On Certainty, ed. G.E.M. Anscombe and G.H. von Wright, trans. D. Paul and G.E.M. Anscombe, Oxford: Basil Blackwell. 